\title{
Optical Absorption Enhancement in Amorphous Silicon Films and Solar Cell Precursors Using the Aluminum-Induced Glass Texturing Method
}

\author{
Nasim Sahraei, ${ }^{1,2}$ Selvaraj Venkataraj, ${ }^{1}$ Premachandran Vayalakkara, ${ }^{1}$ \\ and Armin G. Aberle ${ }^{1,2}$ \\ ${ }^{1}$ Solar Energy Research Institute of Singapore, National University of Singapore, Singapore 117574 \\ ${ }^{2}$ Department of Electrical and Computer Engineering, National University of Singapore, Singapore 117583 \\ Correspondence should be addressed to Nasim Sahraei; nasim.sahraei@nus.edu.sg
}

Received 29 May 2013; Revised 12 October 2013; Accepted 2 November 2013; Published 22 January 2014

Academic Editor: Zofia Stasicka

Copyright (C) 2014 Nasim Sahraei et al. This is an open access article distributed under the Creative Commons Attribution License, which permits unrestricted use, distribution, and reproduction in any medium, provided the original work is properly cited.

\begin{abstract}
One of the key issues of thin-film silicon solar cells is their limited optical absorptance due to the thin absorber layer and the low absorption coefficient for near-infrared wavelengths. Texturing of one or more interfaces in the layered structure of these cells is an important technique to scatter light and enhance the optical pathlength. This in turn enhances the optical absorption of the solar radiation in the absorber layer and improves the solar cell efficiency. In this paper we investigate the effects of textured glass superstrate surfaces on the optical absorptance of intrinsic a-Si:H films and a-Si:H $p-i-n$ thin-film solar cell precursors deposited onto them. The silicon-facing surface of the glass sheets was textured with the aluminium-induced glass texturing method (AIT method). Absorption in both intrinsic silicon films and solar cell precursor structures is found to increase strongly due to the textured glass superstrate. The increased absorption due to the AIT glass opens up the possibility to reduce the absorber layer thickness of a-Si:H solar cells.
\end{abstract}

\section{Introduction}

Thin-film solar cells have potential for low-cost photovoltaic (PV) electricity generation due to inherent advantages such as reduced semiconductor material consumption and the ability to deposit thin films over large areas. However, the thin nature of the absorber limits the optical absorption of the cells. Hydrogenated amorphous silicon $(\mathrm{a}-\mathrm{Si}: \mathrm{H})$ has a very high optical absorption coefficient for photons with energy larger than the bandgap, enabling absorber layer thicknesses of well below $500 \mathrm{~nm}$ for such solar cells. However, light-induced degradation (Staebler-Wronski effect) is a known phenomenon that degrades the efficiency of a-Si:H solar cells when exposed to sunlight. To minimize the lightinduced degradation effect, absorber layer thicknesses of less than $250 \mathrm{~nm}$ are required, which demands excellent light trapping in the structure [1].

To overcome the problem of low optical absorption, various techniques have been tested in the past and reported in the literature to enhance the absorption in these cells, whereby light trapping in thin-film silicon solar cells has been used as early as 1974 [2]. Textured surfaces are known to scatter the light passing through thin-film solar cells, thereby increasing the optical pathlength in the cells and hence the overall absorptance. Advanced optical modeling predicts that light trapping methods, such as texturing the superstrate of thin-film solar cells, can maintain high photocurrents in very thin a-Si:H solar cells [3]. Experimentally, different texturing methods have been used for light scattering in thin-film solar cells, for example, using a textured front transparent conductive oxide (TCO) [4] or etching of the glass sheet $[5,6]$. The TCO film is either textured after its deposition or self-textured during deposition due to the specifics of the deposition process. The scattering properties of a number of differently textured surfaces have been studied in the literature, and the optical haze value has been widely used as a parameter to evaluate the scattering of light within thin-film structures $[3,7,8]$. 


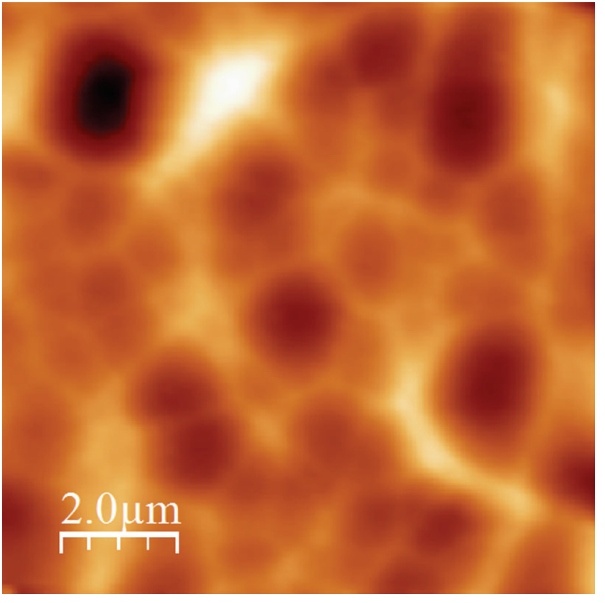

(a)
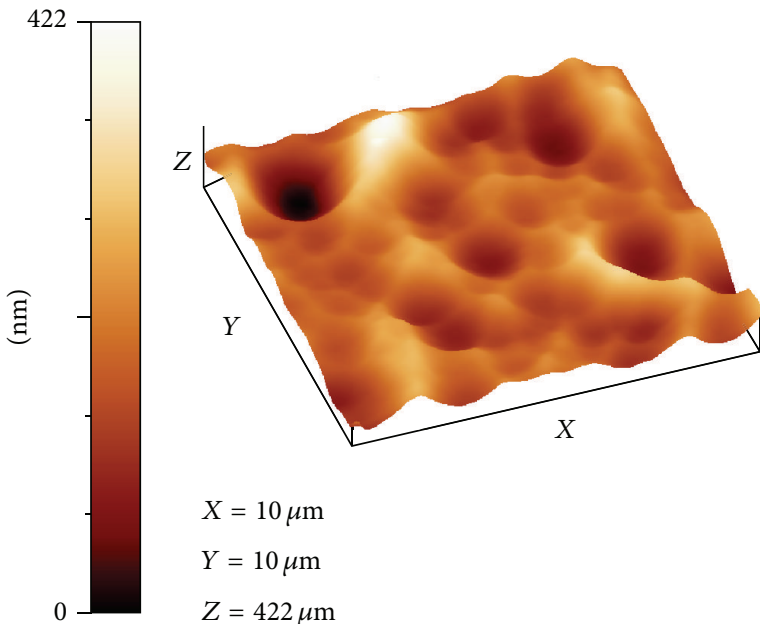

$X=10 \mu \mathrm{m}$
$Y=10 \mu \mathrm{m}$
$Z=422 \mu \mathrm{m}$

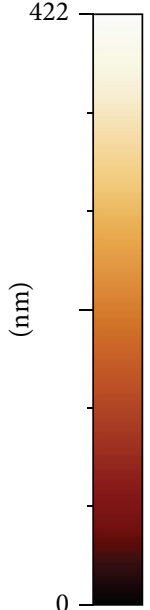

(b)

FIgURE 1: AFM image of the AIT sample after TCO deposition. (a) is the $2 \mathrm{D}$ top view and (b) is the 3D projection of the AFM measurement. The $z$-axis scale is not proportional to the scales of the $x$ - and $y$-axis.

It is well known that front surface texturing, which leads to scattering of light, and a good back surface reflector are both needed to gain the full benefit of optical absorption enhancement. According to Deckman et al. [9], optimum textures have feature sizes that are somewhat larger than the wavelength of the relevant photons, while both very large and very small feature sizes (relative to the wavelength of the relevant photons) do not provide good scattering of the light. The Lambertian limit of increasing the absorption length due to scattering is $m \approx 4 n^{2}$, where $n$ is the refractive index of the absorber layer [9] and $m$ is a measure of the optical absorption enhancement due to both oblique and multiple passes [10]. Considering $n \approx 4$ for $\mathrm{a}-\mathrm{Si}: \mathrm{H}$, the Lambertian limit for optical enhancement is about 60 . However, in actual a-Si:H solar cells, $m$ does not exceed values of about 20 due to parasitic absorption losses [11].

In the present work we use the aluminum-induced texturing (AIT) method $[12,13]$ to texture the silicon-facing surface of soda-lime glass sheets. The AIT glass sheets are used as a superstrate for a-Si:H $p-i-n$ precursor solar cell structures designed to investigate the optical absorptance enhancement. The AIT method was previously used for texturing the glass superstrates of polycrystalline silicon thin-film solar cells to enhance light trapping [14]. The thickness of these polycrystalline silicon thin-film solar cells is about $2-3 \mu \mathrm{m}$. In the present paper, we investigate the optical absorptance of aSi:H films and solar cell precursors on AIT glass superstrates. For comparison, planar glass sheets are also included in the experiments. A layer-by-layer study is performed, enabling the determination of the optical properties of complete a-Si:H $p-i-n$ precursor structures as well as their building blocks. The purpose of the study is to understand the potential for increasing the optical absorption in thin a-Si:H film (thickness less than $300 \mathrm{~nm}$ ) using the AIT glass texturing method. The AIT method is capable of producing textured glass surfaces with a wide range of roughness and lateral feature size. The typical lateral feature size of AIT glass is larger than that of the available textured TCOs. As a result, it is important to investigate whether the AIT glass enhances the optical absorption in a-Si:H thin-film solar cells.

\section{Materials and Methods}

The soda-lime glass sheets used in this study have a thickness of $3 \mathrm{~mm}$. Several glass sheets were textured on the siliconfacing surface with the aluminum-induced texturing (AIT) method [12]. The AIT process was carried out by sputtering a thin $(\sim 100 \mathrm{~nm})$ layer of $\mathrm{Al}$ onto one surface of a glass sheet. The sample was then heated to about $600^{\circ} \mathrm{C}$ in a furnace, causing the $\mathrm{Al}$ to react with the glass. The reaction products were then etched off wet-chemically in a solution of hydrofluoric acid and nitric acid. The textured glass samples were then rinsed in water and dried. Details on the preparation of AIT glass sheets and their properties can be found in the literature $[12,13,15]$. Figure 1 shows an AFM image of a textured glass surface used in this study.

In order to comprehensively study the effect of the AIT glass texture on the absorptance of amorphous silicon thinfilm solar cells, experiments were performed to investigate the optical absorptance of intrinsic a-Si:H films as well as $p-i-n$ a-Si:H solar cell precursors on such glass sheets. For comparison, the same experiments were also performed on 


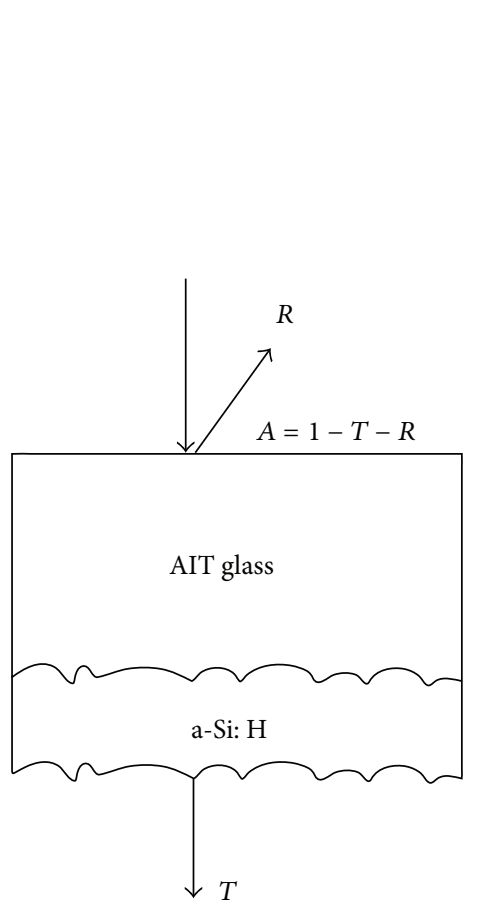

(a)

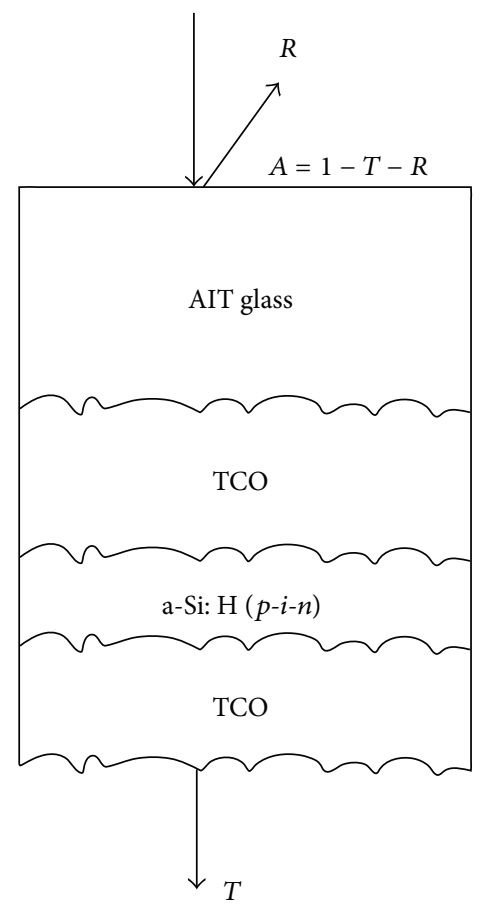

(b)

FIGURE 2: Schematic of the investigated structures on textured glass (not to scale). (a) a-Si:H layer on AIT glass, (b) solar cell precursor on AIT glass.

planar glass sheets. The haze value (see (1)) of the used AIT glass sheets was about $50 \%$.

Two sets of experiments were performed in this work. In the first, an intrinsic a-Si:H film of thickness 115 or $270 \mathrm{~nm}$ was deposited onto planar glass and AIT glass. The resulting sample structure using the textured glass sheet is shown in Figure 2(a). In the second set of experiments, a TCO/p-i$n /$ TCO solar cell precursor was deposited onto planar and AIT glass sheets. The resulting sample structure for the textured glass sheet is shown in Figure 2(b). Both TCOs (front and rear) consist of aluminum-doped zinc oxide ("AZO"). No back surface reflector was deposited, leading to the transmission of some long-wavelength light (see Figure 2). The AZO films were deposited by magnetron sputtering. The thickness of the front AZO film on the planar glass sheet was $900 \mathrm{~nm}$, as measured with a spectroscopic ellipsometer (Sopra, GES 5E, Forouhi-Bloomer model). The thickness of the rear AZO film was about $100 \mathrm{~nm}$, as calculated from the deposition rate of the front AZO film. As in this paper the focus is on investigating the effects of the AIT texture on the absorptance of the a-Si:H thin-film solar cell precursors, no wet-chemical postdeposition AZO texturing step was applied in these experiments. The single-junction $p-i-n$ a-Si:H structure was deposited by plasma-enhanced chemical vapor deposition (PECVD). The thicknesses of the $p$ and $n$ layers were measured by fitting of ellipsometric data (Tauc-Lorentz model), giving 25 and $20 \mathrm{~nm}$, respectively. The thickness of the intrinsic a-Si:H layer was either 115 or $270 \mathrm{~nm}$.

Total transmittance, diffuse transmittance, and total reflectance were measured using a spectrophotometer with integrating sphere (PerkinElmer, Lambda 950). The diffuse transmittance was measured by opening a port at the rear of the integrating sphere and thereby letting the nonscattered transmitted light escape from the integrating sphere. The total absorptance of the sample was then determined using $A=1-$ $T-R$, where $A, T$, and $R$ are the measured total optical absorptance, total transmittance, and total reflectance, respectively. The haze value $H$ of each sample was determined via

$$
H(\%)=\frac{T_{\text {diff }}}{T_{\text {total }}} \times 100,
$$

where $T_{\text {diff }}$ and $T_{\text {total }}$ are the measured diffuse and total transmittances.

Since the absorptance $A$ of the presented solar cell precursor represents the absorptance in the entire structure (i.e., not only in the intrinsic layer), it is not possible to calculate the short-circuit current enhancement for this structure using the total absorptance (i.e., there is no way to quantify the contribution of parasitic absorption to the total absorptance value). In order to compare the absorptance of different samples under solar illumination, a solar spectrum weighted average absorptance $\left(A_{w}\right)$ is calculated via

$$
A_{w}=\frac{\int A(\lambda) \Phi(\lambda) d \lambda}{\int \Phi(\lambda) d \lambda},
$$

where $A(\lambda)$ and $\lambda$ are the absorptance and wavelength, respectively. In this work, $A_{w}$ was calculated by integrating over the wavelength range of $400-800 \mathrm{~nm}$. This wavelength range was chosen to avoid the influence of the optical 


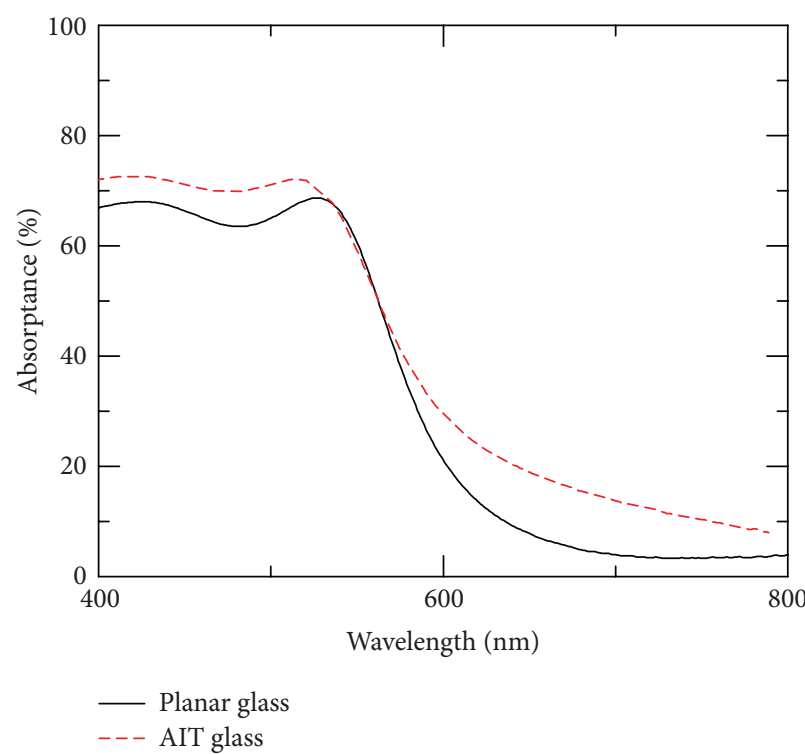

(a) a-Si:H thickness $=115 \mathrm{~nm}$

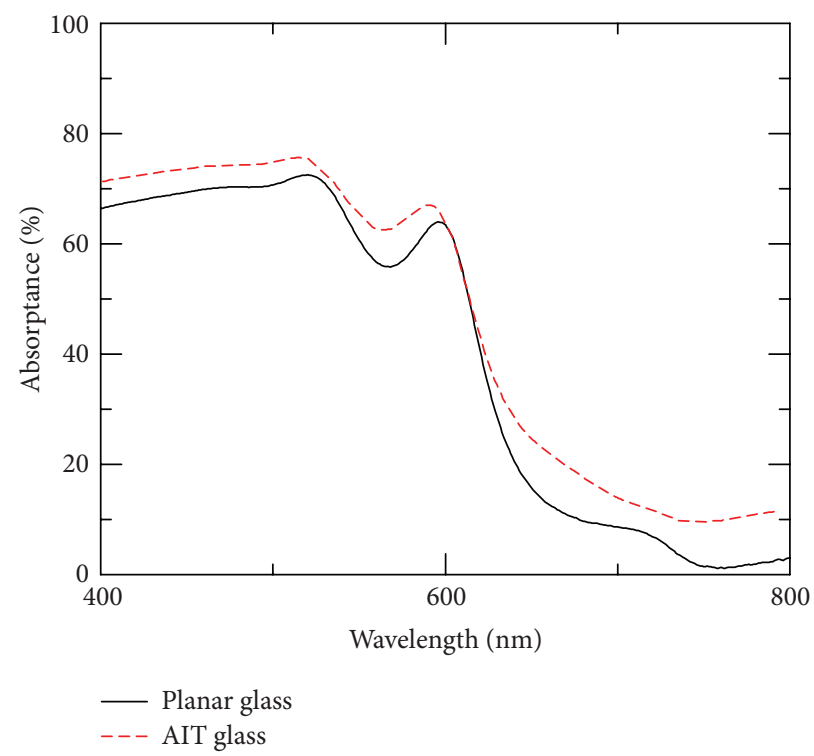

(b) $\mathrm{a}-\mathrm{Si}: \mathrm{H}$ thickness $=270 \mathrm{~nm}$

FIgURE 3: Measured total optical absorptance of glass/a-Si:H (intrinsic) samples on planar glass and AIT glass. The intrinsic a-Si:H layer has a thickness of (a) $115 \mathrm{~nm}$ and (b) $270 \mathrm{~nm}$. The structure of the textured sample is shown in Figure 2(a).

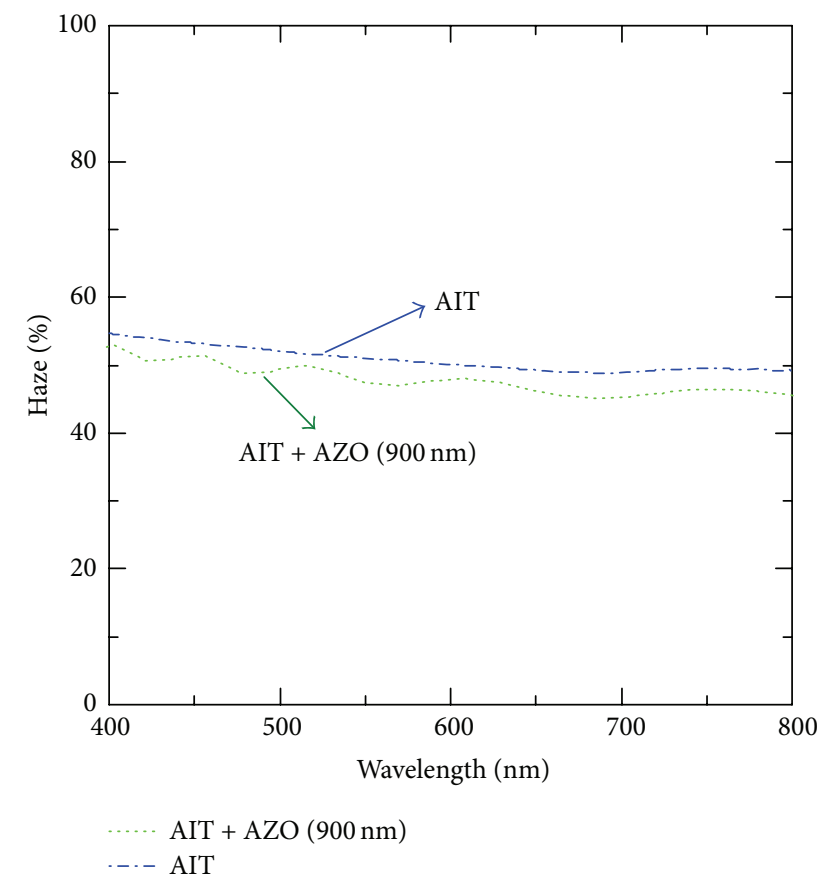

FIGURE 4: Measured haze of the AIT superstrate sample before and after the deposition of a $900 \mathrm{~nm}$ thick AZO film.

absorption of the glass superstrate as well as the TCO layer at short wavelengths. In addition, the chosen wavelength range includes the region in which the absorption coefficient of a-Si:H dramatically decreases, in order to clearly show the optical absorption enhancement induced by the textured surface. The weighting function $\Phi(\lambda)$ represents the photon flux of the solar spectral irradiance (AM1.5G spectrum [16]) within the wavelength range $d \lambda$. The photon flux $\Phi(\lambda)$ can be calculated via

$$
\Phi(\lambda)=\frac{\operatorname{AM} 1.5 \mathrm{G}(\lambda)}{E_{\text {photon }}(\lambda)}
$$

where AM1.5G is the spectral power density of the global solar spectrum at the Earth's surface (sea level) and $E_{\text {photon }}$ is the photon energy at wavelength $\lambda$. This weighting function is applied to ensure that the photon count distribution of the desired solar spectrum is considered.

\section{Results and Discussion}

Figure 3 shows the measured absorptance of a single intrinsic $\mathrm{a}-\mathrm{Si}: \mathrm{H}$ layer on planar and AIT glass for an a-Si:H film thickness of (a) $115 \mathrm{~nm}$ and (b) $270 \mathrm{~nm}$. Clearly, for both $\mathrm{Si}$ film thicknesses, the AIT glass produces a significant optical absorptance enhancement of the samples at both long and short wavelengths. The optical bandgap of both a-Si:H films was calculated from transmittance and reflectance data of planar samples using the method described in [17], giving a value of about $1.7 \mathrm{eV}$ for both films.

In order to better compare the absorptance of the samples, their solar weighted average absorptances $A_{w}$ were calculated as described in Section 2 for the wavelength range 400$800 \mathrm{~nm}$. Table 1 shows the results. It can be seen that by using the AIT glass, the weighted absorptance increases by $6.6 \%$ abs (\% absolute) and $5.6 \%$ abs for the two a-Si:H film thicknesses (115 and $270 \mathrm{~nm}$ ). Since the absorption difference of planar and AIT glass without any film is quite small $\left(2.1 \%_{\mathrm{abs}}\right)$, the gain in the optical absorptance is mainly due to the increased optical pathlength in the silicon film. Table 1 also shows that 


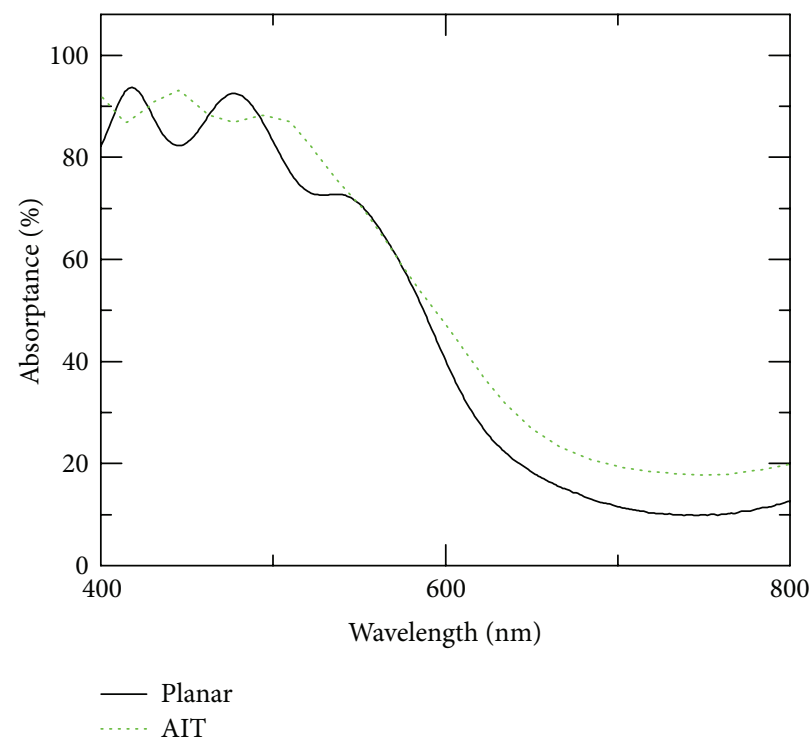

(a) Glass/AZO/pin/AZO, $i=115 \mathrm{~nm}$

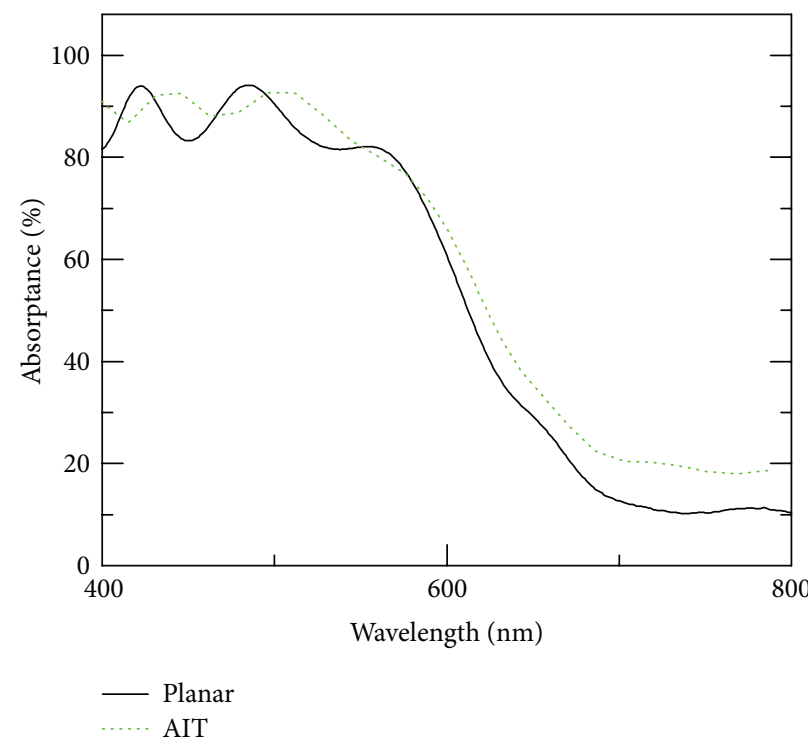

(b) Glass $/ \mathrm{AZO} / \mathrm{pin} / \mathrm{AZO}, i=270 \mathrm{~nm}$

FIGURE 5: Measured absorptance of the a-Si:H solar cell precursors on AIT glass and planar glass. The intrinsic a-Si:H layer thickness is (a) $115 \mathrm{~nm}$ and (b) $270 \mathrm{~nm}$.

TABLE 1: AM1.5G weighted average absorptance $A_{w}$ of the four samples of Figure 3, integrated over the wavelength range $400-800 \mathrm{~nm}$. Also shown are the absorptances of the bare (i.e., noncoated) glass sheets.

\begin{tabular}{lccc}
\hline $\begin{array}{l}\text { Thickness of } \\
\text { the intrinsic } \\
\begin{array}{l}\text { a-Si:H film } \\
(\mathrm{nm})\end{array}\end{array}$ & $\begin{array}{c}\text { Absorptance of } \\
\text { planar sample } \\
(\%)\end{array}$ & $\begin{array}{c}\text { Absorptance of } \\
\text { textured } \\
\text { sample }(\%)\end{array}$ & $\begin{array}{c}\text { Absolute } \\
\text { increase }\left(\%{ }_{\mathrm{abs}}\right)\end{array}$ \\
\hline 0 & 0.2 & 2.3 & N.A. \\
115 & 29.1 & 35.7 & 6.6 \\
270 & 37.1 & 42.7 & 5.6 \\
\hline
\end{tabular}

the effect of texturing the glass is equivalent to using a thicker silicon film on the planar glass sheet. As can be seen, the weighted absorptance of the AIT sample with a $115 \mathrm{~nm}$ thick a-Si:H film is almost the same as that of a $270 \mathrm{~nm}$ thick a$\mathrm{Si}: \mathrm{H}$ film on planar glass. Thus, to absorb the same number of photons in an a-Si:H film on an AIT glass sheet requires less than half the thickness of the a-Si:H film deposited onto the planar glass sheet.

Given the fact that the AIT glass enhances the optical absorptance in an intrinsic amorphous silicon film, we proceeded to make complete amorphous silicon solar cell precursors, as shown in Figure 2(b), and measured their optical absorption properties on a layer-by-layer basis. Again, two intrinsic absorber layer thicknesses (115 and $270 \mathrm{~nm}$ ) were used. Figure 4 shows the haze curve of the AIT glass sheets before and after the deposition of a $900 \mathrm{~nm}$ thick AZO film. As can be seen, the TCO film slightly reduces the optical haze of the structure (by $10 \%$ ) and leads to the emergence of interference fringes. The reasons are slight changes in the surface morphology after TCO deposition as well as some
TABLE 2: AM1.5G weighted average absorptance of the four solar cell precursor samples of Figure 5.

\begin{tabular}{lccc}
\hline $\begin{array}{l}\text { Thickness of } \\
\text { cell's intrinsic } \\
\text { a-Si:H layer } \\
(\mathrm{nm})\end{array}$ & $\begin{array}{c}\text { Absorptance of } \\
\text { planar sample } \\
(\%)\end{array}$ & $\begin{array}{c}\text { Absorptance of } \\
\text { AIT sample } \\
(\%)\end{array}$ & $\begin{array}{c}\text { Absolute } \\
\text { increase (\%) }\end{array}$ \\
\hline 115 & 41.9 & 47.6 & 5.7 \\
270 & 48.7 & 53.8 & 5.1 \\
\hline
\end{tabular}

absorption in the TCO film. Although scattering at the glass/TCO interface is weak due to the small change in refractive index, some additional absorption within the TCO film will occur and thereby reduce the haze value. The parasitic absorption change in the TCO is discussed elsewhere [18].

Figure 5 shows the absorptance of the complete solar cell precursor deposited onto the AIT glass (see Figure 2(b)) for two intrinsic absorber layer thicknesses (115 and $270 \mathrm{~nm}$ ). The figure also shows the absorptance values of identical structures deposited in the same silicon deposition run onto a planar glass sheet. As can be seen, for both intrinsic absorber layer thicknesses, the AIT glass produces significantly higher optical absorptance.

Table 2 shows the weighted absorptance of the solar cell precursors made on AIT glass and on planar glass. It can be seen that the textured glass surface produces a considerable increase in the optical absorptance of the solar cell precursor for both thicknesses of the intrinsic absorber layer. In fact, the absorptance of the AIT solar cell precursor with a $115 \mathrm{~nm}$ thick intrinsic layer is almost the same as that of the planar solar cell precursor with a $270 \mathrm{~nm}$ thick intrinsic layer. Thus, using AIT glass, the thickness of the intrinsic absorber layer can be strongly reduced compared to planar glass. It is 
well known that a thinner absorber layer reduces the lightinduced degradation effect in amorphous silicon solar cells. Hence, AIT glass might provide benefits for industrial amorphous silicon solar cells. It should be noted that the optical absorption enhancement in this study includes parasitic optical absorption. Hence, with respect to the photocurrent gain of actual solar cells, the absorptance gain presented here can be considered as an upper limit for the investigated samples. This upper limit can possibly be improved further by fine-tuning and optimization of the AIT glass texturing method for a-Si:H solar cell structures.

\section{Conclusion}

The effect of glass texturing with the AIT method on the optical absorption of single a-Si:H layers as well as a-Si:H solar cell precursor structures (including TCOs) was experimentally investigated. We found that the textured glass surface produces a strong increase in the optical absorptance of the solar cell precursor for a wide range of intrinsic absorber layer thicknesses (115-270 nm). Further increases seem possible by optimising the surface topography of AIT glass sheets for a-Si:H solar cell applications. Thus, the results of this work suggest that the AIT glass texturing method has potential for industrial amorphous silicon solar cells.

\section{Conflict of Interests}

The authors declare that there is no conflict of interests regarding the publication of this paper.

\section{Acknowledgments}

The authors thank Dr. Ian Marius Peters and Dr. Karen Kristina Forberich for their helpful discussions. SERIS is sponsored by the National University of Singapore and Singapore's National Research Foundation (NRF) through the Singapore Economic Development Board. This work was sponsored by NRF Grant NRF2009EWT-CERP001-037.

\section{References}

[1] S. Guha, J. Yang, and B. Yan, "Amorphous and nanocrystalline silicon solar cells and modules," in Comprehensive Semiconductor Science and Technology, B. Pallab, F. Roberto, and K. Hiroshi, Eds., pp. 308-352, Elsevier, Amsterdam, The Netherlands, 2011.

[2] D. Redfield, "Multiple-pass thin-film silicon solar cell," Applied Physics Letters, vol. 25, no. 11, pp. 647-648, 1974.

[3] M. Zeman, R. van Swaaij, J. W. Metselaar, and R. E. I. Schropp, "Optical modeling of a-Si:H solar cells with rough interfaces: effect of back contact and interface roughness," Journal of Applied Physics, vol. 88, no. 11, pp. 6436-6443, 2000.

[4] T. Tiedje, B. Abeles, J. M. Cebulka, and J. Pelz, "Photoconductivity enhancement by light trapping in rough amorphous silicon," Applied Physics Letters, vol. 42, no. 8, pp. 712-714, 1983.

[5] W. Zhang, E. Bunte, J. Worbs et al., "Rough glass by 3D texture transfer for silicon thin film solar cells," Physica Status Solidi (C), vol. 7, no. 3-4, pp. 1120-1123, 2010.
[6] O. Isabella, C. Battaglia, C. Ballif, and M. Zeman, "Modulated surface-textured substrates based on etched glass," in Proceedings of the Technical Digest of the 21st International Photovoltaic Science and Engineering Conference, p. 4A-2O-13, Fukuoka, Japan, 2011.

[7] D. Dominé, P. Buehlmann, J. Bailat, A. Billet, A. Feltrin, and C. Ballif, "Optical management in high-efficiency thin-film silicon micromorph solar cells with a silicon oxide based intermediate reflector," Physica Status Solidi-Rapid Research Letters, vol. 2, no. 4, pp. 163-165, 2008.

[8] C.-C. Lin, W.-L. Liu, and C.-Y. Hsieh, "Scalar scattering model of highly textured transparent conducting oxide," Journal of Applied Physics, vol. 109, no. 1, Article ID 014508, 2011.

[9] H. W. Deckman, C. R. Wronski, H. Witzke, and E. Yablonovitch, "Optically enhanced amorphous silicon solar cells," Applied Physics Letters, vol. 42, no. 11, pp. 968-970, 1983.

[10] E. Yablonovitch, "Statistical ray optics," Journal of Optical Society of America, vol. 72, no. 7, pp. 899-907, 1982.

[11] S. S. Hegedus and R. Kaplan, "Analysis of quantum efficiency and optical enhancement in amorphous Si p-i-n solar cells," Progress in Photovoltaics, vol. 10, no. 4, pp. 257-269, 2002.

[12] A. G. Aberle, P. I. Widenborg, and N. Chuangsuwanich, "Glass texturing," European Patent EP1613562 B1, 2011.

[13] V. Premachandran, S. Venkataraj, J. Wang et al., "Aluminium induced glass texturing process on borosilicate and soda- lime glass superstrate for thin-film solar cells," in Proceedings of the 37th IEEE Photovoltaic Specialist Conference, IEEE, Seattle, Wash, USA, 2011.

[14] P. I. Widenborg and A. G. Aberle, "Polycrystalline silicon thinfilm solar cells on AIT-textured glass superstrates," Advances in OptoElectronics, vol. 2007, Article ID 24584, 7 pages, 2007.

[15] S. Venkataraj, J. Wang, P. Vayalakkara, and A. G. Aberle, "Light scattering enhancement by double scattering technique for multijunction thin-film silicon solar cells," IEEE Journal of Photovoltaics, vol. 3, no. 2, pp. 605-612, 2013.

[16] "Standard tables for reference solar spectral irradiances: direct normal and hemispherical on $37^{\circ}$ tilted surface," ASTM G17303, ASTM International, West Conshohocken, Pa, USA, 2008, http://www.astm.org/.

[17] Y. Hishikawa, N. Nakamura, S. Tsuda, S. Nakano, Y. Kishi, and Y. Kuwano, "Interference-free determination of the optical absorption coefficient and the optical gap of amorphous silicon thin films," Japanese Journal of Applied Physics, Part 1, vol. 30, no. 5, pp. 1008-1014, 1991.

[18] N. Sahraei, P. Vayalakkara, S. Venkataraj, and A. G. Aberle, "Effect of glass texturing on the absorptance of a-Si:H p-i-n structures," in Proceedings of the Technical Digest of the 21st International Photovoltaic Science and Engineering Conference, p. 4D-2P-25, Fukuoka, Japan, 2011. 

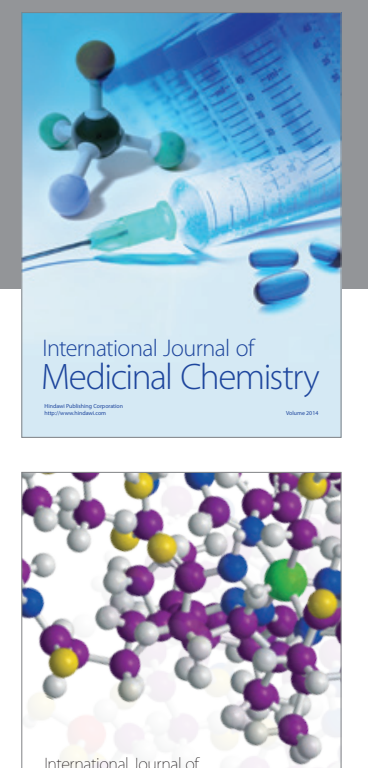

\section{Carbohydrate} Chemistry

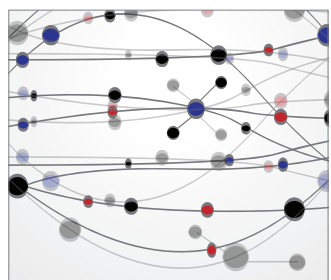

The Scientific World Journal
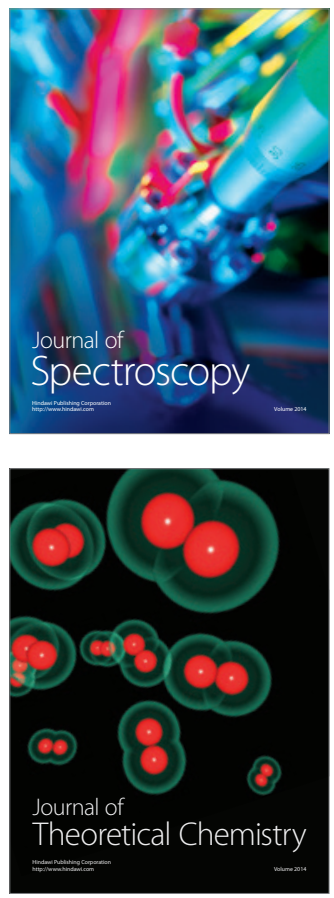
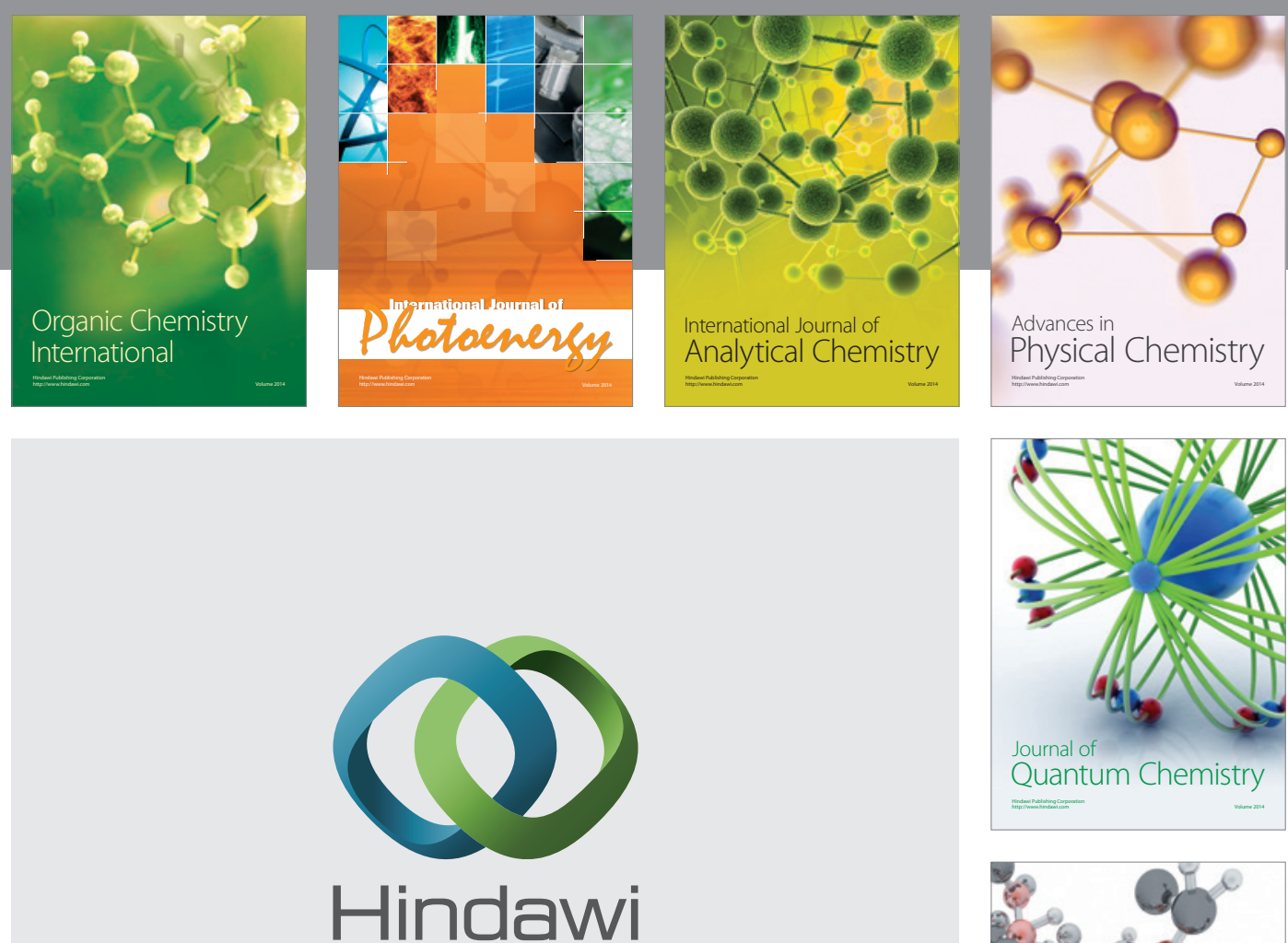

Submit your manuscripts at

http://www.hindawi.com

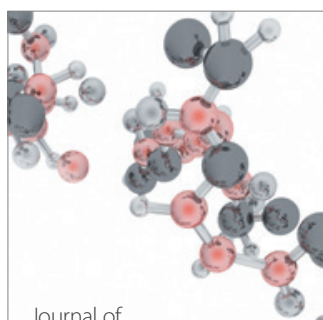

Analytical Methods

in Chemistry

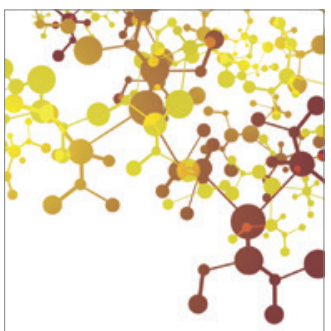

Journal of

Applied Chemistry

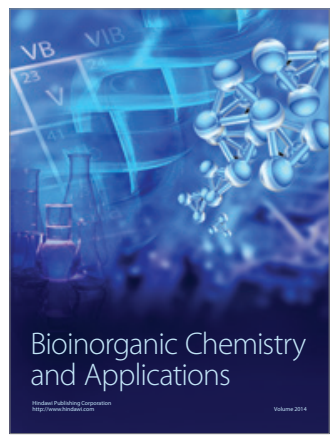

Inorganic Chemistry
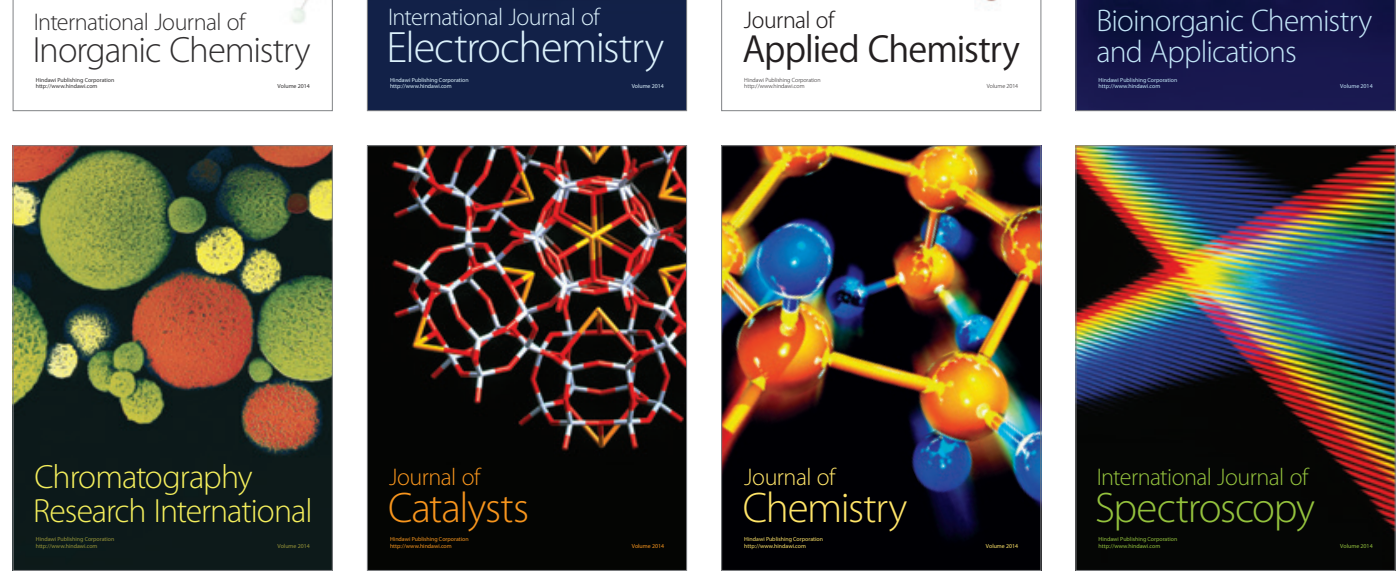